\title{
Conservation management in the face of uncertainty: effectiveness of four options for managing Hector's dolphin bycatch
}

\author{
Elisabeth Slooten* \\ Department of Zoology, University of Otago, PO Box 56, Dunedin, New Zealand
}

\begin{abstract}
New Zealand's endemic Hector's dolphins Cephalorhynchus hectori overlap with gillnet and trawl fisheries throughout their geographic range. The catch rate in commercial gillnets has been estimated using independent observers. No quantitative estimates are available for bycatch in recreational gillnets or trawl fisheries. The catch rate (per dolphin, per $\mathrm{km}$ of gillnet, per year) in commercial gillnets was used in a population viability analysis to estimate past and future population sizes. Total population size today (7873, coefficient of variation [CV] 0.16) was estimated at $27 \%$ of population size in 1970 (29316, CV 0.16), before a major expansion of commercial gillnetting. The species matches IUCN criteria for 'endangered'. The North Island subspecies matches criteria for 'critically endangered'. Current management, which includes 2 protected areas, is not sufficient to halt population declines. Hector's dolphin populations are predicted to continue declining to 5475 (CV 0.20$)$ by 2050. Creating 4 strategically placed protected areas would allow population recovery towards 1970 levels, with an estimated $47 \%$ probability of reaching $50 \%$ of 1970 population size by 2050 (proportion of 5000 model runs in which final population size was at or above this reference level). Reducing fisheries mortality to levels approaching zero shows the strongest promise of meeting national and international guidelines for managing dolphin bycatch, with a $59 \%$ probability of reaching $50 \%$ of 1970 population size by 2050 .
\end{abstract}

KEY WORDS: Hector's dolphin · Fishing $\cdot$ Bycatch $\cdot$ Extinction $\cdot$ Risk $\cdot$ Population viability Resale or republication not permitted without written consent of the publisher

\section{INTRODUCTION}

Hector's dolphins Cephalorhynchus hectori are endemic to New Zealand waters. Small populations are found around the South Island (7270 individuals, CV 0.16; Slooten et al. 2004) and off the North Island west coast (111 individuals, CV 0.44; Slooten et al. 2006a). Since the early 1970s, Hector's dolphins have been caught in commercial gillnet fisheries (Taylor 1992, Baird \& Bradford 2000).

The situation for Hector's dolphins in New Zealand is representative of many species affected by fisheries bycatch and other conservation problems. There is a recognised impact on the species. Preliminary efforts have been made to quantify and manage the impact; however, data indicate that the impact remains unsus- tainable. Further management decisions are needed, despite uncertainty about biological parameters and the continuing level of impact (Martien et al. 1999, Burkhart \& Slooten 2003, DOC \& MFish 2007).

The present paper presents a population viability analysis for Hector's dolphin populations around New Zealand, based on recent estimates of dolphin abundance (Dawson et al. 2004, Slooten et al. 2004, 2006a), estimates of catch rate from the commercial gillnet fishery (Baird \& Bradford 2000) and fishing effort data from the Ministry of Fisheries. This analysis indicates negative effects of fisheries mortality, at the local level, on regional populations and on the overall spatial distribution of the species. Population sizes are estimated for 1970, before commercial gillnetting rapidly expanded in New Zealand waters (Massey \& Francis 1989, 
Dawson 1991), on the basis of a back-calculation using catch rates for the commercial gillnet fishery. Hector's dolphins are also known to be caught in inshore trawl fisheries (Baird \& Bradford 2000, Starr \& Langley 2000, DOC \& MFish 2007), and bycatch in trawl fisheries and amateur gillnets is likely to extend several decades further back. Dolphin bycatch in trawling and recreational gillnets could not be included in this analysis because no quantitative estimates of catch rate are available. Therefore, the estimates of population status presented here are likely to be optimistic.

The purpose of this analysis is to provide population information for managers on the conservation status of Hector's dolphin populations and in particular on the effectiveness of management options designed to reduce fisheries mortality for this species. The analyses include uncertainty in input parameters to ensure that this is not an obstacle to science-based decision making.

\section{MATERIALS AND METHODS}

In modelling, we used the 16 fisheries management areas for which fishing effort data were available (see Fig. 1): the same areas used by Martien et al. (1999) and Burkhart \& Slooten (2003). Hector's dolphins show strong site fidelity. Their home range extends for an average of $31 \pm 2.43$ (SE) km of coastline, and individuals are seen in the same area throughout the year and over many years (Bräger et al. 2002). The movement rate between areas at this scale has been estimated at less than $1 \%$ of the population per year (Fletcher et al. 2002). Results are also reported for 4 larger regions for which management solutions are being discussed as part of the development of a Threat Reduction Plan for Hector's dolphins (DOC \& MFish 2007): North Island west coast (Areas 1-4) and the South Island west (Areas 5-8), east (Areas 9-13) and south coasts (Areas 14-16). These 4 regional management areas are broadly based on regions with genetically distinct populations (Pichler et al. 1998). Results on conservation status are presented for the 2 taxonomic units listed by the IUCN and the New Zealand Department of Conservation - at the species level and for the North Island subspecies (also known as Maui's dolphin).

I used the modelling approach outlined in Martien et al. (1999) and Burkhart \& Slooten (2003). Stochastic elements of the model include future fishing effort, population growth rate, the number of dolphins caught and movement from one area to another in any one year.

A Schaefer (1954) surplus production model was used:

$$
N_{t+1}=N_{t}\left[1+\left(\lambda_{\text {max. }}-1\right)\left(1-N_{t} / K\right)\right]-N_{t} C_{t}
$$

where $N_{t}$ is population size at time $t_{1} \lambda_{\max }$ is maximum annual population growth rate, $K$ is carrying capacity (defined here as population size in 1970) and $C_{t}$ is the proportion of the population killed by entanglement in gillnets in year $t$.

The proportion of the dolphin population killed each year ( $C_{t}$ in Eq. 1 ) was estimated using fishing effort, the entanglement rate and the size of the area:

$$
C_{t}=M E_{t}
$$

where $E_{t}$ is fishing effort at time $t$ (metres of gillnet per $\mathrm{km}^{2}$ ) and $M$ is dolphin entanglement rate (proportion of dolphin population caught per unit of fishing effort, $E$ ), estimated from an observer programme in Area 12 (Baird \& Bradford 2000). This is the only area for which a successful observer programme has been carried out. The number of dolphins caught per year in each area was estimated using a binomial distribution, with the number of dolphins in the area as the number of 'trials' and the catch rate as the probability of any one dolphin becoming entangled in a gillnet.

The New Zealand Ministry of Fisheries provided data on commercial fishing effort. For each area, I divided the fishing effort data by the size of the area $\left(\mathrm{km}^{2}\right)$ (Burkhart \& Slooten 2003). The Sea Food Industry Council assisted in identifying and excluding fishing effort that did not affect dolphins. For example, most gillnetting in Area 11 was deep water netting for groper, terakihi, and school sharks (depths $>100 \mathrm{~m}$ ) that occurred outside Hector's dolphin range (C. Sutton, Sea Food Industry Council, pers. comm.). For this analysis, I therefore considered only $10 \%$ of the total fishing effort taking place in Area 11.

Fishing effort in New Zealand was first reported in 1975 (M. Struzak, Ministry of Fisheries, pers. comm.). From 1975 to 1982, fishermen recorded the time of year and the total weight of fish caught, but were not required to specify the location or the amount of effort. Beginning in 1983, a new system for reporting fishing effort was implemented. The Ministry of Fisheries divided the waters surrounding New Zealand into statistical fishing areas and fishing effort data were summarised by area. There are 52 statistical fishing areas; Hector's dolphins occur in 16 of these (see Fig. 1), and some gillnet effort occurs in all 16. In mid-1986, the Quota Management System (QMS) was introduced, changing the magnitude and distribution of fishing effort in New Zealand waters (Clark et al. 1988, DOC \& MFish 1994). The level of fishing effort for the years 1970 to 1982 was therefore estimated by taking the average of the effort reported between 1983 and 1985, before implementation of the QMS. Ministry of Fisheries staff felt that fishing effort data from before 1983, for this fishery, were not sufficiently reliable to be used in these analyses. Future fishing effort was based on 
the mean level of fishing effort after the introduction of the QMS (i.e. 1987 onwards, as fishing effort changed halfway through 1986 from pre- to post-QMS levels). Year-to-year variability in fishing effort was based on the mean and standard deviation (SD) of fishing effort between 1987 and 2006. For each year during each simulation, a value was randomly selected from a distribution with this mean and SD to represent the level of fishing effort for that year.

All calculations were carried out in Microsoft Excel, using Visual Basic macros for repetitive calculations. I used the goal seek function in Excel to estimate the population size in 1970 that was consistent with the current estimate of population size for each area. This process was repeated 5000 times, sampling from the distributions for population growth and population size, to result in a distribution for 1970 population size for each area. These 5000 values for population size in 1970, population size in 2007 and population growth rate from the back calculations were then used as the starting point for forward projections to estimate population size in 2050. A similar method of back-calculation is described in Smith \& Polachek (1979), Barlow \& Hanan (1995) and Martien et al. (1999). The distribution for population size was based on the most recent population estimate for each area (see Slooten et al. 2004, 2006a).

For each run of the model, a maximum population growth rate was randomly selected from a uniform distribution between 1.018 and $1.049 \mathrm{yr}^{-1}$ to reflect uncertainty in the estimation of this parameter. The highest and lowest population growth rates span the range used by Martien et al. (1999). These growth rates were estimated by Slooten \& Lad (1991). The results indicated that Hector's dolphin, like most other small cetaceans, has a low potential for population growth. Maximum population growth rates of 1.018 to 1.049 $\mathrm{yr}^{-1}$ are likely to be the maximum possible for Hector's dolphin populations. For a similar analysis see Reilly \& Barlow (1986). A very similar range of maximum population growth rates ( 2 to $4 \%$ ) has been estimated for other dolphin species (Perrin \& Reilly 1984). These maximum population growth rates are expected to be achieved in very small populations, with little competition for food, space or other resources. To represent environmental stochasticity, the maximum population growth rate was expressed as a normal distribution with a mean corresponding to the population growth rate selected for that run of the model (as above) and an SD of $6 \%$, based on Slooten et al. (2000). For each year during each simulation, a maximum population growth rate was randomly selected from this normal distribution to give a slightly different maximum population growth rate each year. The SD for adult survival has been estimated at $6 \%$ (Slooten et al. 2000) based on the variance component estimation procedure in the mark-recapture programme MARK (White \& Burnham 1999). Sensitivity analyses for previous Hector's dolphin models indicate that increasing the survival rate by $1 \%$ results in a very similar increase in population growth rate (e.g. Slooten \& Lad 1991, Slooten et al. 2000).

The effect of different movement rates was explored. Research on Hector's dolphin movement includes studies of photographically identified individuals at 3 locations on the east coast, 3 locations on the west coast and 1 location on the south coast of the South Island. In addition, more detailed mark-recapture work was carried out at Banks Peninsula and an adjacent area from Timaru to the Rakaia River mouth. These studies indicate that the movement rate is $<1 \%$ of the population $\mathrm{yr}^{-1}$ at the scale of the 16 fishing areas used in the model (Bräger 1998, Bräger et al. 2002, Martien et al. 1999, Fletcher et al. 2002). Movement was modelled stochastically, with the movement rate $(0,1$ or $5 \%$ of the population for the sensitivity trials, $1 \%$ for all other analyses) used as the probability of each individual migrating from its original area to an adjacent area in any given year. As for bycatch, the outcome for each individual was the result of a Bernouilli trial using a binomial distribution with the movement rate as the probability of success.

Population sizes in 1970, 2007 and 2050 are presented as distribution maps to indicate the potential effects of bycatch on the overall geographical range and distribution of the species, as well as the potential effectiveness of different management options. The year 2050 was chosen as a reasonable timepoint for assessing the outcome of potential management decisions taken in 2007. This allows sufficient time (just over three generations) to show the effect of different levels of protection. Population size in 2050 was also compared with the original population size in 1970 and with half of the 1970 level, as marine mammal legislation in some countries requires that populations are kept at or above half of the original unexploited population size (e.g. Wade 1998, Taylor et al. 2000).

Four options for future management were compared. These were based on management decisions under evaluation by government agencies and stakeholders in New Zealand as part of the development of a Threat Reduction Plan for Hector's dolphin (DOC \& MFish 2007). The first management option (A) is a continuation of current management, which includes 2 protected areas created in 1988 and 2003, respectively. A protected area on the North Island west coast includes Areas 1 and 2 and part of Area 3. The Banks Peninsula Marine Mammal Sanctuary covers the central part of Area 12. Some fisheries mortality continues in both of these protected areas. Management Option B consists 
of making the 2 existing protected areas $100 \%$ effective by extending their boundaries and eliminating fishing mortality from Areas 1 to 3 (North Island protected area) and Area 12 (which includes the Banks Peninsula Marine Mammal Sanctuary). Option C involves creating 4 large protected areas by eliminating fishing mortality in Areas 1 to 3 (North Island), Areas 6 to 8 (South Island west coast), Areas 11 to 12 (South Island east coast) and Areas 14 to 16 (South Island south coast). Option D eliminates fishing mortality for all populations (Areas 1 to 16).

For Options B to D regulations are assumed to be $100 \%$ effective, reducing fisheries mortality to zero in the areas under protection. The effectiveness of Option A is based on data on the proportion of the population found inside and outside the Banks Peninsula Marine Mammal Sanctuary, estimated using a series of linetransect surveys (Dawson et al. 2004, Rayment et al. 2006, Slooten et al. 2006b). The proportion of Hector's dolphin groups sighted inside the 4 nautical mile sanctuary boundary was $78.6 \%$ in summer and $35.1 \%$ in winter (Slooten et al. 2006b). Adding Hector's dolphins found inside Area 12 but north and south of the sanctuary boundaries, led to an estimate of $50.8 \%$ of the population being outside the sanctuary in summer and $78 \%$ being outside the sanctuary in winter (Slooten et al. 2006b). The average exposure of dolphins to gillnets was based on these distribution data as well as the relative amount of fishing in summer and winter (Slooten et al. 2006b). Starr \& Langley (2000) estimated that $71 \%$ of the gillnet fishing effort (in total metres of net used) occurs in spring and summer (October to March) and the remaining $29 \%$ in autumn and winter (April to September). The proportion of dolphins exposed to gillnet fisheries in any given year was therefore estimated as a weighted average, multiplying the proportion of dolphins found outside the sanctuary and the proportion of fishing effort for each season to estimate an average exposure to gillnets of $58.7 \%$ (see Slooten et al. 2006b for more details). This is an optimistic estimate of the level of protection, as there have been continued dolphin catches inside the sanctuary (DOC \& MFish 2007) partly because recreational gillnetting is still allowed inside the sanctuary for 8 mo of the year and partly due to illegal gillnetting within the sanctuary. The estimate above assumes that all individuals within the sanctuary are fully protected and that dolphins are exposed to gillnet entanglement only outside the sanctuary boundaries.

It is more difficult to estimate the proportion of the North Island Hector's dolphin population still exposed to gillnets. Dolphin sightings are regularly made in the harbours and south of the protected area and there are indications that the dolphins may range further offshore than the 4 nautical mile offshore bound- ary (Department of Conservation unpubl. data, D. Breen pers. comm.). In addition, trawling continues inside the protected area and gillnetting continues inside the harbours. Gillnet effort inside the harbours is higher than the level for the open coast before the protected area was created. Taking all of these factors into account, I used $25 \%$ as a conservative estimate of the proportion of the population that is not protected.

The results of this modelling exercise were also used to determine whether new data on abundance and bycatch rates warrant any changes in the listing of Hector's dolphin on the IUCN Red List of Threatened Species (IUCN 2006). I ran the model for 3 generations, to match criterion A4: 'observed, estimated, inferred, projected or suspected population size reduction ... over any 10 years or 3 generations, whichever is longer (up to a maximum of 100 years)' where the reduction or its causes may not have ceased, or may not be understood, or may not be reversible (IUCN 2001, p. 12). Generation length is defined as the average age of parents of the current cohort, estimated at $13 \mathrm{yr}$ for Hector's dolphins (IUCN 2001). The simulations ran for the 3 generations from 1970 to 2009. A species is listed as Critically Endangered if the estimated rate of decline is equal to or greater than $80 \%$, and as Endangered or Vulnerable if the rate of decline is $50 \%$ or $30 \%$ or more, respectively.

\section{RESULTS}

Distribution and abundance maps indicate the effects of fisheries mortality on individual areas and the overall spatial distribution of the species. Between 1970 and 2007 dolphin densities declined in all areas (Fig. 1). In 1970, only 3 areas had fewer than 100 individuals. By 2007, this was the case for 11 of the 16 areas and the overall population had become more fragmented. Estimates of current population size were of the order of $10,20,30$ and $50 \%$ of 1970 population size, for the North Island, South Island east, west and south coast populations, respectively, and $27 \%$ for the species as a whole (Table 1). Predicted population sizes in 2050 depended on the rate of movement; a rate of $1 \%$ of the population (Fig. 2) represents the most likely outcome for 2050. Fig. 2 also indicates the outcome if the rate of movement is much lower or much higher than estimated from field data. As expected, an increased rate of movement appears to result in a better prognosis for relatively low density areas but a worse outcome for high density areas. With a movement rate close to that estimated in the field, populations adjacent to protected populations benefited from that protection (e.g. Areas 11 and 13). However, pro- 


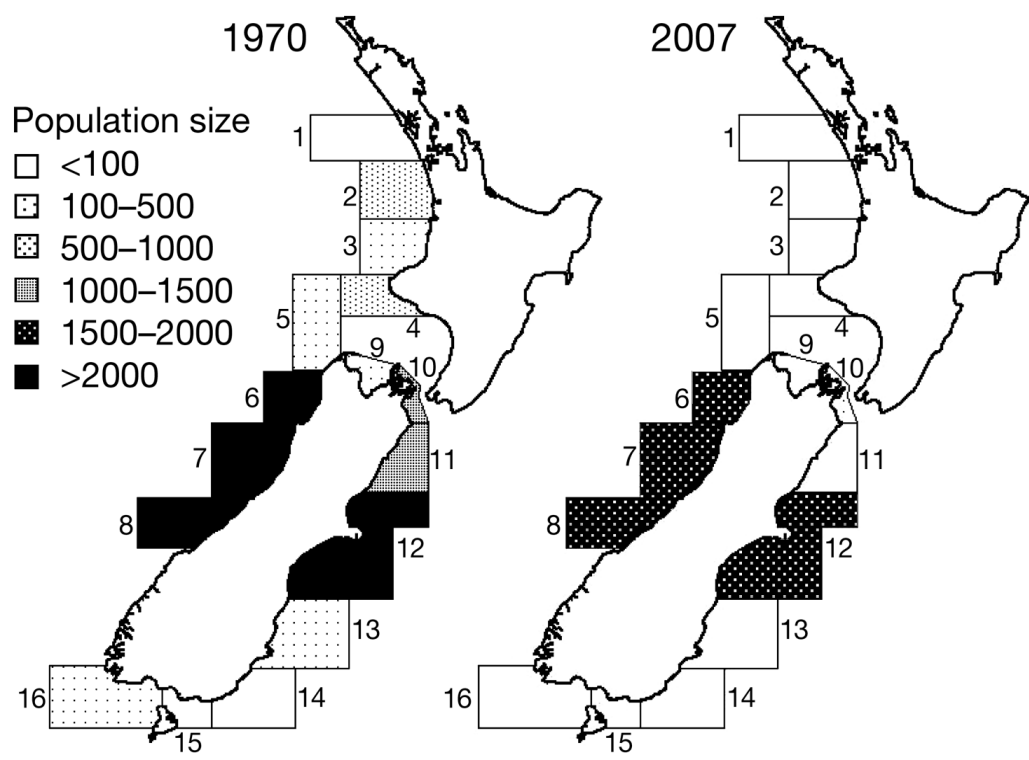

Fig. 1. Cephalorhynchus hectori. Changes in Hector's dolphin distribution between 1970 and 2007. Current population estimates are based on most recent line-transect surveys; 1970 estimates are based on back-calculation using current population estimates and estimates of fishing effort and dolphin catch rate

Table 1. Cephalorhynchus hectori. Population size estimates (coefficient of variation in parentheses) for 4 regional areas and total population in 1970 (before gillnet use expanded markedly in New Zealand), in 2007 and current population size as a fraction of 1970 population size

\begin{tabular}{|c|c|c|c|}
\hline & 1970 & 2007 & $2007 / 1970$ \\
\hline North Island & $1729(0.51)$ & $117(0.44)$ & 0.07 \\
\hline South Island west & $16513(0.22)$ & $5459(0.21)$ & 0.33 \\
\hline South Island east & $10812(0.26)$ & $2169(0.27)$ & 0.20 \\
\hline South Island south & $262(0.26)$ & $133(0.20)$ & 0.51 \\
\hline Total for species & $29316(0.16)$ & $7873(0.16)$ & 0.27 \\
\hline
\end{tabular}

tected areas (e.g. Areas 1 to 3 and 12) fared better if there was less movement. The most likely outcome was depletion for most areas compared to dolphin numbers in 2007 (Fig. 2).

Future distribution and abundance was strongly affected by the management option chosen. Under current management (Option A) dolphin numbers were predicted to continue declining in most areas (Table 2, Fig. 3). The highest density areas all had declining dolphin numbers, including Area 12, which contains the Banks Peninsula Marine Mammal Sanctuary. There were small increases in some of the low density areas (e.g. Areas 5, 11 and 13). However, all of these stayed well below 500 individuals. At the regional level, only the very small North Island population was predicted to grow. Total population size continued to decline from the current level of 7873 (CV 0.16) to 5475 (CV 0.20) in 2050 (Tables 1 \& 2).
Option B involved making the existing 2 protected areas $100 \%$ effective. This resulted in predicted population increases in the protected areas and adjacent areas. However, most other populations continued to decline. Dolphin numbers were predicted to decline under Option B for 3 of the 4 regions and for the species as a whole (Tables 1 \& 2). Management Option $\mathrm{C}$ involved creating 4 large, completely effective, protected areas. This management option has the potential to result in population recovery (Table 2) with an estimated $47 \%$ probability of reaching $50 \%$ of 1970 population size by 2050 (Table 3). Dolphin numbers in most areas were predicted to increase, including areas in the centre of the geographic distribution (Fig. 3).

Eliminating fisheries mortality (Option D) is likely to result in increases in all areas and substantial population recovery (59\% probability of reaching $50 \%$ of 1970 population size by 2050, Table 3). Options $\mathrm{C}$ and D result in population recovery towards 1970 levels. Total population size in 1970 was estimated at 29316 (CV 0.16). Total population size in 2007 was estimated at 7873 (CV 0.16), i.e. $27 \%$ of 1970 population size. Current management is likely to result in a further decrease to $19 \%$ of 1970 population size by 2050. Options B, C and D are predicted to result in population sizes of $24 \%, 49 \%$ and $53 \%$, respectively, of 1970 levels by 2050 . The total population did not recover to 1970 population size in any runs of the population model, regardless of which management option was chosen (Table 3). The probability of recovering to $50 \%$ of the 1970 levels by 2050 (proportion of 5000 runs in which final population size was at or above this reference level) was $>0$ only for Options C and D (Table 3). The probability of recovery to half of the 1970 levels by 2050 was estimated at better than 50:50 only for Option D (Table 3).

Another key difference between options C and D concerns estimated dolphin numbers in the areas linking North and South Island (Areas 3, 4, 5 and 9). These 4 areas separate the North Island and South Island Hector's dolphins, and are crucial in terms of population fragmentation and ensuring that populations are sustainable throughout the natural range of the species. For example, protecting Area 4 substantially increased the recovery rate for Areas 1 to 3 (Fig. 3, Table 2).

The estimated rate of decline over 3 generations (1970 to 2009) was $74 \%$ for the species as a whole, matching the IUCN criteria for Endangered (observed, estimated, inferred, projected or suspected rate of decline $\geq 50 \%$ ). The estimated rate of decline was $93 \%$ 


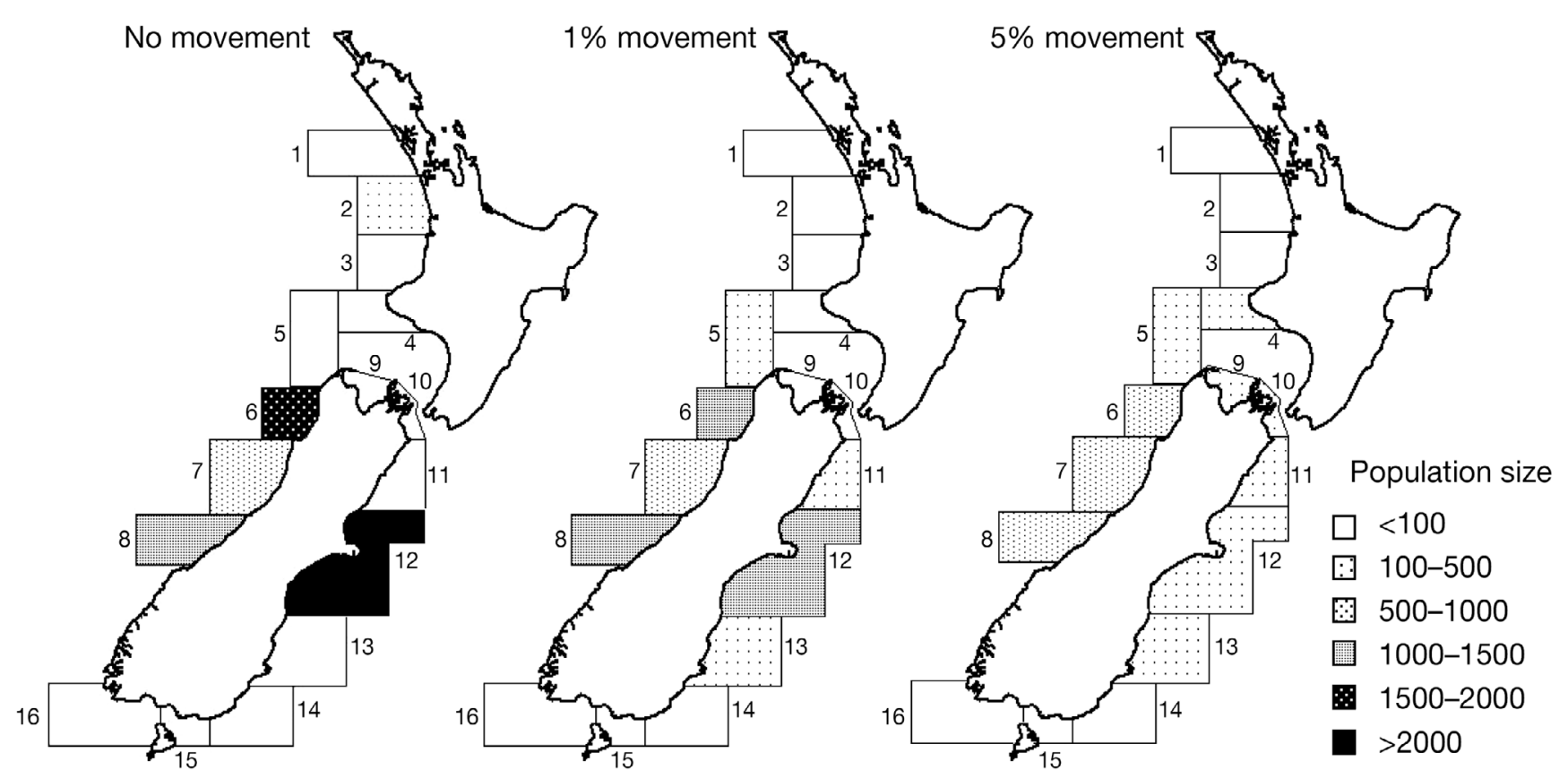

Fig. 2. Cephalorhynchus hectori. Estimated population size in 2050, depending on movement rate (proportion of the population moving from one area to an adjacent area each year)

Table 2. Cephalorhynchus hectori. Population size estimates (coefficient of variation in parentheses) for 2050 depending on the management option chosen: Option A is based on current management; the other options eliminate fisheries mortality in Areas 1 to 3 and 12 (Option B), in Areas 1 to 3,6 to 8, 11 to 12 and 14 to 16 (Option C) and in Areas 1 to 16 (Option D)

\begin{tabular}{|lrrrr|}
\hline & Option A & Option B & Option C & \multicolumn{1}{c|}{ Option D } \\
\hline North Island & $176(0.46)$ & $286(0.46)$ & $294(0.45)$ & $466(0.27)$ \\
South Island west & $3437(0.27)$ & $3436(0.27)$ & $9973(0.21)$ & $10088(021)$ \\
South Island east & $1738(0.35)$ & $3071(0.28)$ & $3851(0.30)$ & $4641(0.26)$ \\
South Island south & $124(0.21)$ & $132(0.19)$ & $196(0.22)$ & $215(0.20)$ \\
Total for species & $5475(0.20)$ & $6925(0.20)$ & $14314(0.17)$ & $15411(0.16)$ \\
\hline
\end{tabular}

areas. Not surprisingly, dolphin density in protected areas tended to increase faster when movement rates were relatively low. The higher the movement rate, the more unprotected areas were a drain on any nearby protected areas. For example, the population in the Banks Peninsula Marine Mammal Sanctuary is exposed to gillnet fisheries north and south of the sanctuary. Higher levels of movement reduce the risk of depletion for populations adjacent to the sanctuary, but increase the

for the North Island subspecies (which has been separately listed by both the IUCN and New Zealand Department of Conservation) matching the criteria for Critically Endangered (rate of decline $\geq 80 \%$ ).

\section{DISCUSSION}

Between 1970 and 2007, Hector's dolphin densities declined throughout the geographic range of the species, and the population became more fragmented. If current management continues, populations are still expected to be below half of their 1970 population size in 2050. The current listing of Hector's dolphin as Endangered, and the North Island population as Critically Endangered (IUCN) was supported by this analysis.

Movements of individuals from one population to another affected predicted population sizes in several risk for the sanctuary area. In general, low rates of movement resulted in relatively greater population fragmentation. If movement rates were much higher than estimated, this would be expected to lead to less fragmentation but greater population depletion throughout the geographic range. High movement rates tend to lead to the poorest outcome for the species as a whole (Martien et al. 1999). A rate of movement close to that estimated in the field resulted in an intermediate outcome, with continuing population declines and increased population fragmentation overall.

By reducing population size in some areas more than others, fisheries mortality appears to have played a role in shaping the current distribution of Hector's dolphins. For example, the areas linking North Island and South Island (Areas 4, 5 and 9) have relatively high levels of fishing effort and low dolphin numbers. Likewise, fishing impacts may explain the 


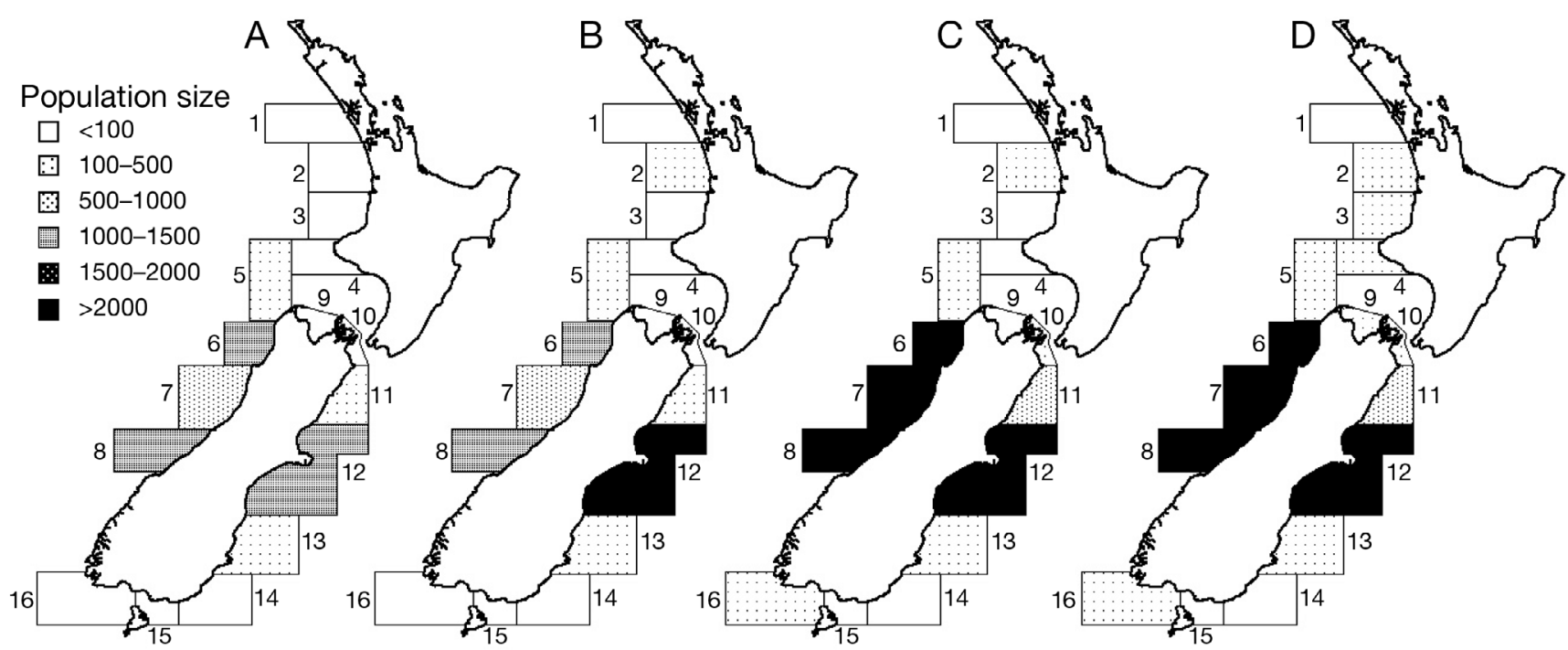

Fig. 3. Cephalorhynchus hectori. What could be achieved by 2050 under current management (Option A), eliminating fisheries mortality in Areas 1 to 3 and 12 (Option B), in Areas 1 to 3, 6 to 8, 11 to 12 and 14 to 16 (Option C) and in Areas 1 to 16 (Option D)

Table 3. Cephalorhynchus hectori. Probability of the total population size for the species having recovered to 1970 levels $(K)$ and half 1970 levels by 2050 (proportion of 5000 model runs in which final population size was at or above these reference levels), depending on the management option chosen. See Table 2 for details of Options A to D

\begin{tabular}{|lcccc|}
\hline & Option A & Option B & Option C & Option D \\
\hline Recovered to $K$ & 0.00 & 0.00 & 0.00 & 0.00 \\
Recovered to $0.5 K$ & 0.00 & 0.00 & 0.47 & 0.59 \\
\hline
\end{tabular}

relative isolation of the Te Waewae Bay population (Area 16) from Hector's dolphin populations along the east coast of the South Island. There was an increase in population fragmentation in this area between 1970 and 2007. Clearly, habitat also plays a role. For example, the gap between Areas 8 and 16, the Fiordland area, consists mostly of very deep water habitat, which does not appear to be favoured by Hector's dolphins. Surveys around New Zealand indicate that Hector's dolphins are concentrated in waters $<100 \mathrm{~m}$ deep (Dawson et al. 2004, Slooten et al. 2004, $2006 \mathrm{a}, \mathrm{b})$. However, relative levels of fishing activity in different parts of this species' range also appear to have a strong influence on the distribution of Hector's dolphins.

Analysis of likely past distribution patterns and the trajectory of change is just as important for future management of the species as estimates of future population change. When history and the historical trajectory of change are ignored, a system is more likely to be falsely perceived as being stable and pristine (Steneck \& Carlton 2001, Hughes et al. 2007). In recent years, ecologists have focused increasingly on the cumulative and interactive effects of environmental impacts (Jackson 2001). As a result, the management goal becomes population (or ecosystem) recovery rather than maintaining current abundance and distribution.

The choice of management option strongly influenced predicted distribution and abundance. Continuation of current management measures is not sufficient to halt further population decline, let alone result in recovery. For example, dolphin numbers in Area 12, which includes the Banks Peninsula Marine Mammal Sanctuary (created in 1988), are expected to continue to decline under current management. The boundaries of the sanctuary would need to be extended to ensure the viability of this population (see also Slooten et al. 2006b).

Several other studies have found that for small populations even very low levels of impact can pose a serious conservation threat. For example, for North Atlantic right whales, preventing the deaths of 2 or 3 adult females per year would substantially reduce extinction risk (Fujiwara \& Caswell 2001). Likewise, for turtles in the Cayman Islands, even a relatively low level of mortality from 'traditional' hunting may impede population recovery sought through conservation and management actions (Bell et al. 2006).

Recent management has been strongly focussed on protecting North Island Hector's dolphin populations. This subspecies is 'Critically Endangered' and certainly needs effective protection if it is to stabilise or recover. Even if human impacts can be reduced to levels approaching zero, the North Island populations may take many decades to reach non-threatened levels and population persistence is far from guaranteed. 
The top priority now, in order to ensure population recovery throughout the geographic range, is to better protect South Island populations. Several of the South Island areas have very small and rapidly declining numbers of dolphins. Like the North Island Hector's dolphins, these populations need immediate management action. Other South Island areas have relatively large, but declining abundance. A relatively low level of management intervention now would ensure that these populations do not decline to critically endangered levels. If South Island populations are left unprotected and decline towards critical levels, much stronger and more rapid management intervention would be necessary in a few decades.

Making the 2 existing protected areas $100 \%$ effective would be an improvement for populations in the protected areas and immediately adjacent areas. However, it is insufficient to halt the decline in total population size and would achieve little in terms of preventing further population fragmentation.

Option C, creating 4 protected areas, would provide protection for some populations in each region where Hector's dolphins are found (North Island west coast, South Island east, west and south coasts). This option would promote recovery in terms of abundance, distribution and reducing population fragmentation. However, by 2050 Option C still only offers a $47 \%$ probability of recovery to half of the original 1970 population size.

Eliminating fisheries mortality for all areas where Hector's dolphins are found (Option D) would result in substantial population increases. Several areas, however, would still have relatively low population numbers in 2050. Some of these areas appear to have had low numbers of Hector's dolphins at least since 1970; others have been so severely depleted over the last $35 \mathrm{yr}$ that it will take longer than $45 \mathrm{yr}$ to recover. One of the most important differences between Options C and $\mathrm{D}$ is the substantial reduction in fragmentation. Several areas are unlikely to recover by 2050 unless Option D is chosen. This is particularly noticeable for the areas linking the North Island subspecies with South Island Hector's dolphin populations. Option D would also provide a much greater potential for recovery for the North Island subspecies, Maui's dolphin.

Overall, Option D results in substantial recovery of most populations. This would allow management to move out of 'crisis management' mode and into strategic management towards long-term stability and recovery throughout the species' geographic range. Dealing with fisheries mortality in a comprehensive way would provide breathing space to investigate other apparently less severe impacts on the species, including pollution, marine mining, tourism and potential future impacts like tidal energy generation.
Reducing fisheries mortality to levels approaching zero (i.e. by using only fishing methods that do not catch dolphins in areas where Hector's dolphins are found) would be necessary to make meaningful progress towards the likely original distribution and abundance (before human influence).This option is likely to be unpopular with fishers and politicians. Acceptability of this solution is increased by the fact that similar approaches have been taken in other areas. For example, in waste management the target is often 'zero waste'. The philosophy among people working in this area appears to be that greater and faster progress will be made if the target is 'zero waste' than if the target is less ambitious. By setting an ambitious target like zero waste or zero fishing mortalities it is more likely that the true potential for reducing impacts will be realised. Dolphin mortalities from fishing could be virtually eliminated in the protected areas by using only fishing methods that do not catch dolphins. Gillnets and trawl fisheries are a serious threat to Hector's dolphins. However, there is no need for all fishing to stop in the protected areas. Fishing using all other fishing methods (e.g. fish traps, craypots, line fishing) could continue with little, if any, effect on Hector's dolphins.

It is important to emphasize that the simulations above assume that fishers using fishing methods that catch dolphins would change to other fishing methods, rather than move their fishing operation from a protected to an unprotected area. If gillnet and trawl fisheries are displaced from protected areas to adjacent areas where Hector's dolphins are found, this would result in much less optimistic outcomes than those reported above. More data from observer programmes would help answer the question of what proportion of fishing effort is displaced to other areas and to improve estimates of the entanglement rate. So far, an observer programme has been carried out in only 1 area (Area 12).

National and international standards provide a context for evaluating the 4 management options considered here. For example, the New Zealand Marine Mammals Protection Act (1978) states that fisheries mortality should be managed to ensure that threatened species 'achieve non-threatened status as soon as reasonably practicable, and in any event within a period not exceeding 20 years'. Management goals under US legislation include the following: (1) Maintaining populations above their Optimum Sustainable Population (OSP) level. OSP is defined as a population size exceeding the level at which the population has its maximum net productivity (greatest net annual increment in population size resulting from reproduction minus natural mortality). In a simple logistic model, such as the one used here, populations are at OSP if they exceed $50 \%$ 
of the original (pre-impact population). (2) If a population is endangered or threatened, bycatch levels should be negligible and in no case should bycatch delay recovery of endangered species by more than $10 \%$ of the estimated recovery time in the absence of human impact. (3) Populations should not be permitted to diminish below the point at which they cease to be a significant functioning element in the ecosystem of which they are a part. Goals 1 and 3 are specified in the US Marine Mammal Protection Act and goal 2 is included in the guidelines for preparing marine mammal stock assessments (Barlow et al. 1995).

The New Zealand Marine Mammal Action Plan includes the following goals for Hector's dolphins: 'self-sustaining populations throughout the species natural range' and 'reduce bycatch to near zero'. The plan also recommends that a recovery group be set up, and a recovery plan be developed with specific management goals for Hector's dolphins. Option D comes closest to achieving these statutory goals, with a $59 \%$ probability of reaching $50 \%$ of 1970 population size by 2050 and a substantial reduction in population fragmentation. It is important to reiterate that 1970 populations were already impacted by gillnet and trawl fisheries before that time. Also, the analyses carried out here include mortalities from commercial gillnet fisheries only. There are no quantitative estimates of mortalities from trawl fisheries and recreational gillnets. Therefore, the results presented above are relatively optimistic.

Ecosystem-scale networks of marine protected areas are increasingly favoured over small, isolated reserves. Recent examples include the Northwestern Hawaiian Island Marine National Monument and the proposed global network of high seas marine reserves (Roberts et al. 2006). Marine protected areas have the potential to protect marine mammals, provided they are large enough to be ecologically relevant to the species concerned and provided that protection measures effectively target impacts on the species (e.g. Hoyt 2005). For the smallest and most vulnerable Hector's dolphin populations (e.g. North Island west coast, South Island south coast) human impacts would need to be reduced to zero to ensure that these populations recover. For the larger populations, the main threat, mortalities in gillnet and trawl fisheries, urgently needs to be managed. Research and management response to other less serious threats (e.g. boat strikes, effects of climate change) should follow management of the key threats, rather than cause delays in management of the clearly serious threat caused by fisheries mortality.

It is important to ensure that efforts at management and species recovery are matched to the scale of past and ongoing impact. Conservation efforts often come late because warning signs are unrecognised or unheeded, and management is often small-scale and fragmented (Hughes et al. 2007). Even the most rigorous management of remnant areas could be too little, too late. For example, populations of the seacow Dugong dugong have declined by $97 \%$ over the last 30 yr along $1000 \mathrm{~km}$ of coastline in Queensland, Australia. Assuming that hunting, mortalities in fishing nets and habitat degradation can all be controlled, it is estimated that recovery of the species to the levels of the 1970s (which were already severely depleted) will take at least $120 \mathrm{yr}$. The dugong's potential for population growth ( 2 to $3 \% \mathrm{yr}^{-1}$ ) is very similar to that of Hector's dolphins and other dolphin species.

\section{CONCLUSIONS}

A comparison of alternative management options indicates that current management is not sufficient to halt population declines in Hector's dolphins. Creating 4 strategically placed protected areas would reduce the risk of population declines and fragmentation. Even then, some populations would remain at very low levels up to 2050. Fisheries mortality would need to be reduced to levels approaching zero to have a reasonable chance of achieving goals for managing marine mammal populations in national and international legislation. This could be achieved by using only dolphinsafe fishing methods in areas where Hector's dolphins are found, and would substantially increase population size and reduce population fragmentation. In addition to the obvious conservation benefits, reducing the use of gillnets and trawling would also substantially reduce economic costs associated with monitoring continuing kills (of dolphins and other protected species) and ensure that they are sustainable (Dawson \& Slooten 2005). The recommendation of the New Zealand Marine Mammal Action Plan to reduce Hector's dolphin bycatch to near zero should be implemented as soon as possible for 3 reasons: (1) it is the only option that shows a realistic prospect of achieving national and international guidelines for marine mammal protection; (2) the monitoring and policing costs associated with weaker management solutions are unrealistic in the medium or long term; (3) reducing bycatch to near zero leaves a greater range of management options open for the future. If Hector's dolphin populations further decline and fragment, future conservation management will become increasingly expensive, logistically difficult and likely to fail. This is well recognised in other marine conservation issues. If management intervention is delayed until the species or ecosystem has gone beyond the point of no return, even the most rigorous management of remnant areas will be too little, too late (e.g. Hughes et al. 2007). 
Acknowledgements. I am very grateful to Barbara Taylor and Karen Martien (US National Marine Fisheries Service), Stephanie Burkhart (US Coast Guard) and Steve Dawson (Otago University) for their contributions to an earlier version of this population model and for discussions about population viability analysis and conservation issues for dolphins and whales. The modelling approach used in this paper has been discussed with representatives from government agencies, the fishing industry, recreational fishers and other stakeholders in meetings that formed part of the development of a 'Threat Reduction Plan' for Hector's dolphins and in other meetings organised by the New Zealand Department of Conservation and Ministry of Fisheries. The information on conservation status reported in this paper was also discussed at an IUCN workshop reviewing cetacean listings for the Red List of endangered species (La Jolla, January 2007). I thank the participants in these workshops for their constructive criticism and helpful suggestions.

\section{LITERATURE CITED}

Baird SJ, Bradford E (2000) Estimation of Hector's dolphin bycatch from inshore fisheries, 1997-98 fishing year. Published Client Report on Contract 3024, Department of Conservation, Wellington. Available at: http:// csl.doc.govt.nz/upload/documents/science-and-technical/ CSL3024.pdf

Barlow J, Hanan D (1995) An assessment of the status of harbor porpoise in central California. In: Bjorge A, Donovan GP (eds) Biology of phocoenids: a collection of papers. International Whaling Commission, Cambridge, p 123-140

Barlow J, Swartz SL, Eagle TC, Wade PR (1995) US Marine mammal stock assessments: guidelines for preparation, background, and a summary of the 1995 assessments. NOAA Tech Memo NMFS-OPR-6

Bell CD, Blumenthal JM, Austin TJ, Solomon, JL, EbanksPetrie G, Broderick AC, Godley BJ (2006) Traditional Caymanian fishery may impede local marine turtle population recovery. Endang Species Res 2:63-69

Bräger S (1998) Behavioural ecology and population structure of Hector's dolphin. PhD thesis, University of Otago, Dunedin

Bräger S, Dawson SM, Slooten E, Smith S, Stone GS, Yoshinaga A (2002) Site fidelity and along-shore range in Hector's dolphin, an endangered marine dolphin from New Zealand. Biol Conserv 108:281-287

Burkhart SM, Slooten E (2003) Population viability analysis for Hector's dolphin (Cephalorhynchus hectori): A stochastic population model for local populations. NZ J Mar Freshwat Res 37:553-566

Clark IN, Major PJ, Mollett N (1988) Development and implementations of New Zealand's ITQ management system. Mar Resour Econ 5:325-349

Dawson SM (1991) Incidental catch of Hector's dolphin in inshore gillnets. Mar Mamm Sci 7(3):283-295

Dawson SM, Slooten E (2005) Management of gillnet bycatch of cetaceans in New Zealand. J Cetacean Res Manag 7: $59-64$

Dawson SM, Slooten E, DuFresne S, Wade P, Clement D (2004) Small-boat surveys for coastal dolphins: Line-transect surveys for Hector's dolphins (Cephalorhynchus hectori). Fish Bull 201:441-451

DOC and MFish (Department of Conservation, and Ministry of Agriculture and Fisheries) (1994) Review of the Banks Peninsula Marine Mammal Sanctuary: a paper for public comment. Canterbury Conservancy Miscellaneous Report Series No. 3. Department of Conservation, Christchurch

DOC and MFish (Department of Conservation, and Ministry of Agriculture and Fisheries) (2007) Hector's dolphin threat management discussion document, April 2007. Available at: www.fish.govt.nz/en-nz/Environmental/ default.htm

Fletcher D, Dawson S, Slooten E (2002) Designing a markrecapture study to allow for local emigration. J Agric Biol Environ Stat 7(4):1-8

Fujiwara M, Casswell H (2001) Demography of the endangered North Atlantic right whale. Nature 414:- 537-541

Hoyt E (2005) Marine Protected Areas for whales, dolphins and porpoises: a world handbook for cetacean habitat conservation. Earthscan Publishing, Sterling, VA

Hughes TP, Bellwood DR, Folke C, Steneck RS, Wilson J (2005) New paradigms for supporting the resilience of marine ecosystems. Trends Ecol Evol 20:380-386

IUCN (2001) IUCN Red List Categories and Criteria : Version 3.1. IUCN Species Survival Commission. IUCN, Gland and Cambridge

IUCN (2006) IUCN Red List of Threatened Species. Available at: www.iucnredlist.org

Jackson JBC, Kirby MX, Berger WH, Bjorndal KAand 15 others (2001) Historical overfishing and the recent collapse of coastal ecosystems. Science 293:629-638

Martien KK, Taylor BL, Slooten E, Dawson S (1999) A sensitivity analysis to guide research and management for Hector's dolphin. Biol Conserv 90:183-191

Massey BR, Francis MP (1989) Commercial catch composition and reproductive biology of rig (Mustelus lenticulatus) from Pegasus Bay, Canterbury, New Zealand. NZ J Mar Freshw Res 23:113-120

Perrin WF, Reilly SB (1984) Reproductive parameters of dolphins and small whales of the family Delphinidae. Rep Int Whaling Comm Spec Issue 6:97-133

Pichler FB, Dawson SM, Slooten E, Baker CS (1998) Geographic isolation of Hector's dolphin populations described by mitochondrial DNA sequences. Conserv Biol 12:676-682

Rayment W, Dawson SM, Slooten E, Childerhouse SJ (2006) Offshore distribution of Hector's dolphin at Banks Peninsula. Department of Conservation Research and Development Series 232. Department of Conservation, Wellington

Reilly SB, Barlow J (1986) Rates of increase in dolphin population size. Fish Bull 84:527-533

Roberts CM, Mason L, Hawkins JP (2006) Roadmap to recovery: a global network of marine reserves. Environment Department, University of York, York

Schaefer MB (1954) Some aspects of the dynamics of populations important to the management of commercial fisheries. Bull Inter-Am Trop Tuna Comm 1:27-56

Slooten E, Lad F (1991) Population biology and conservation of Hector's dolphin. Can J Zool 69:1701-1707

Slooten E, Fletcher D, Taylor BL (2000) Accounting for uncertainty in risk assessment: case study of Hector's dolphin mortality due to gillnet entanglement. Conserv Biol 14: $1264-1270$

Slooten E, Dawson SM, Rayment WJ (2004) Aerial surveys for coastal dolphins: abundance of Hector's dolphins off the South Island west coast, New Zealand. Mar Mamm Sci 20: $117-130$

Slooten E, Dawson SM, Rayment WJ, Childerhouse SJ (2006a) A new abundance estimate for Maui's dolphin: What does it mean for managing this critically endangered species? Biol Conserv 128:576-581

Slooten E, Rayment WJ, Dawson SM (2006b) Offshore distrib- 
ution of Hector's dolphins at Banks Peninsula: Is the Banks Peninsula Marine Mammal Sanctuary large enough? NZ J Mar Freshwat Res 40(2):333-343

Smith TD, Polachek T (1979) Analysis of a simple model for estimating historical population sizes. Fish Bull 76: 771-779

Starr P, Langley A (2000) Inshore fishery observer programme for Hector's dolphins in Pegasus Bay, Canterbury Bight, 1997/98. Published Client Report on Contract 3020, Department of Conservation, Wellington. Available at: http://csl.doc.govt.nz/upload/documents/science-andtechnical/CSL3020.pdf

Steneck RS, Carlton JT (2001) Human alterations of marine communities: students beware! In: Bertness M, Gaines S,

Editorial responsibility: Rebecca Lewison,

San Diego, California, USA
Hay M (eds) Marine community ecology. Sinauer Press, Sunderland, MA, p 445-468

Taylor B, Wade PR, de Master DP, Barlow J (2000) Incorporating uncertainty into management models for marine mammals. Conserv Biol 14:1243-1252

Taylor PR (1992) Incidental catch of non-fish species in setnets in New Zealand waters. New Zealand Fisheries Assessment Research Document 92/21. Ministry of Fisheries, Wellington

Wade PR (1998) Calculating thresholds to the human-caused mortality of cetaceans and pinnipeds. Mar Mamm Sci 14(1):1-37

White GC, KP Burnham (1999) Program MARK: survival estimation from populations of marked animals. Bird Study 46:120-139

Submitted: February 13, 2007; Accepted: July 2, 2007

Proofs received from author(s): July 31, 2007 